\title{
Fluctuating asymmetry of silver birch Betula pendula Roth in industrial and recreational zones of the South-West of St. Petersburg
}

\author{
Grigorii Kozlov ${ }^{1}$, Mikhail Pushkarev ${ }^{1, *}$, Anastasia Trubnikova ${ }^{1}$, Anastasia Goreva ${ }^{1}$, \\ Miroslava Ivanova ${ }^{1}$, Natalia Fedorova ${ }^{1}$, and Aleksandr Sovestnov ${ }^{1}$ \\ ${ }^{1}$ Saint Petersburg State Institute of Technology (Technical University), 190013, Moskovsky prospect, \\ 26, Saint-Petersburg, Russia
}

\begin{abstract}
The paper contains information on the fluctuating asymmetry of the silver birch in the recreational and industrial zones of the SouthWest of St. Petersburg. It is proposed to use the fluctuating asymmetry of silver birch to substantiate the choice of locations for isolating promising strains - destructors of toxic organic pollutants.
\end{abstract}

\section{Introduction}

Despite the large number of publications on the problem of biodegradation of hazardous and toxic substances and materials, the isolation of new cultures and consortia of microorganisms capable of carrying out their degradation does not lose its relevance and allows the discovery of new highly effective destructors. However, most of the samples taken from soils, grounds, waste, etc. allows isolating destructors that perform decomposition, but whose efficiency is quite mediocre. In some cases [1], strainsdestructors isolated from locations with extremely high pollution (toxic waste landfills) or soils of cities with a long industrial history show the ability to biodegrade very highly concentrated toxic substances, but such samples can be isolated very rarely. Since microbiological manipulations are rather laborious, we propose to use bioindication to substantiate sampling points [2]. Various indicator plants grow in different regions. However, the largest number of works is devoted to silver birch [3,4], which grows almost everywhere in the temperate climate zone. Joint sampling of soil and herbarium of an indicator plant with further ranking of samples based on the results of bioindication or preliminary mapping of the area where it is planned to take samples for isolation of destructors in order to select the most contaminated location will significantly reduce the volume of routine microbiological experiments. As a rule, researchers use soil samples taken from local pollution spots, at landfills for toxic organic waste, etc. However, in any case, we are dealing with an expert assessment of the pollution level of the location in which the sample is taken. The purpose of this paper is to study the fluctuating asymmetry of silver birch in recreational zones of the South-West of St. Petersburg for preliminary

\footnotetext{
${ }^{*}$ Corresponding author: malexpush@,bk.ru
} 
mapping of the locations for the search for destructors of benzopyrene and other controlled polycyclic aromatic hydrocarbons (PAH EPA) [5].

\section{Materials and methods}

The herbarium was sampled in September 2020 at the following points (Figure 1): 1 - next to the Experimental plant for mechanized processing of municipal waste; 2 - next to the ring road interchange; 3 - Alexandrino park; 4 - Novatorov Boulevard. The herbarium was collected using conventional methods. The coordinates were determined by a GPS navigator. Measurements were made with a ruler with a graduation of $0.5 \mathrm{~mm}$. This measurement accuracy is completely sufficient for the tasks facing this study. The fluctuating asymmetry was calculated using the formula (1) [3]:

$$
A s_{f l}=2 * \frac{L_{1}-L_{2}}{L_{1}+L_{2}}
$$

where: $L_{1}$ - length of the left lower leaf vein; $L_{2}$-length of the right lower leaf vein.

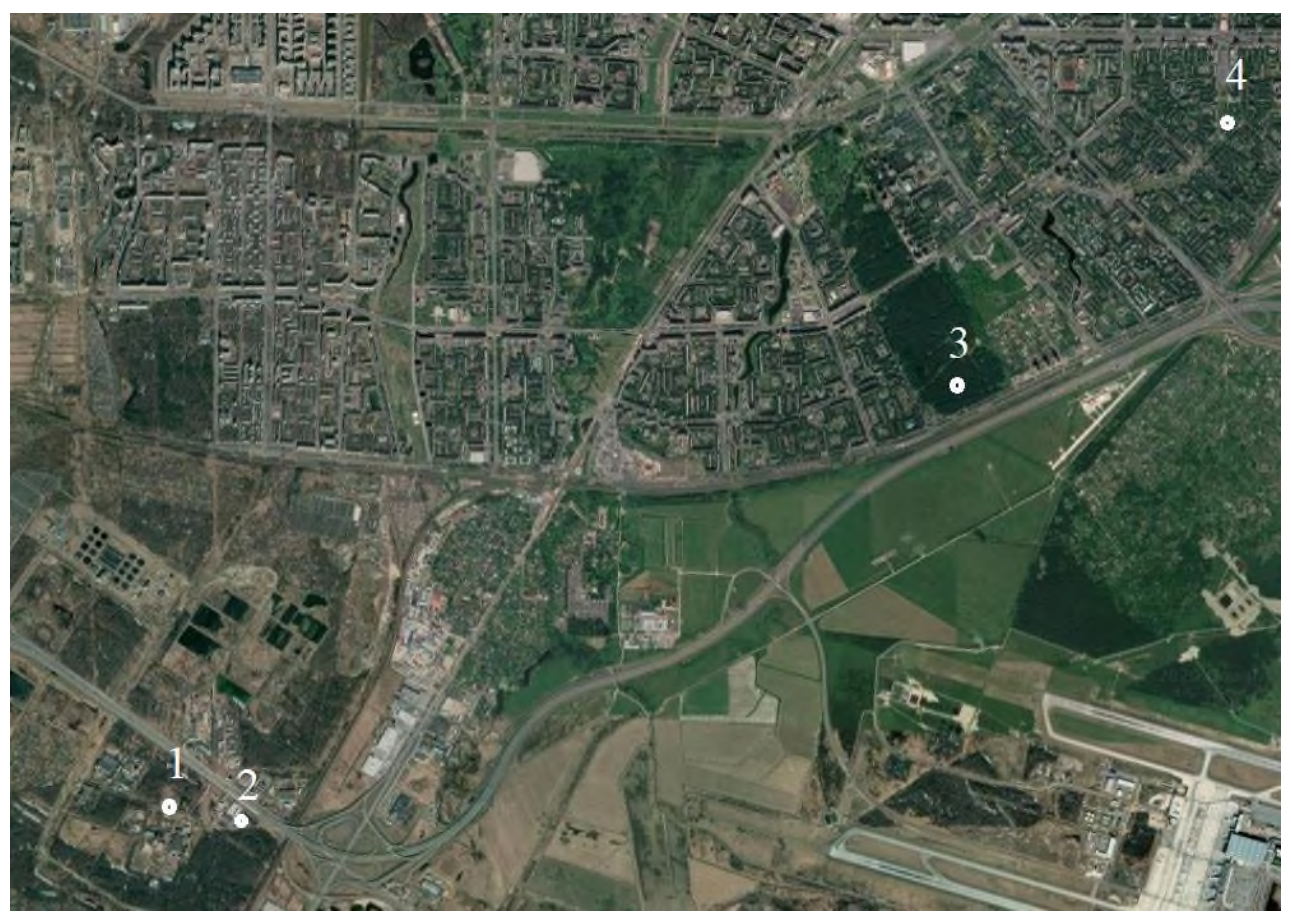

Fig. 1. Locations of herbarium selection. The coordinates of the points are given in Table 1 .

To eliminate the "observer effect", the collection of herbarium and measurements were carried out by different researchers.

\section{Results and discussion}

To substantiate a sufficient sample size in assessing the value of the index of fluctuating asymmetry, the dependence of the mean value of fluctuating asymmetry on the sample size 
was studied. Graphs of dependences of the fluctuating asymmetry index for different locations are shown in the graphs (Figures 2-5).

It follows from the graphs that the average value begins to fluctuate around its general value in a rather narrow range with a sample size of 400 variants and more. Analysis of the graphs of the dependence of fluctuating asymmetry on the sample size makes it possible to avoid false positive and false negative results, since the calculation of the average value for further analysis is performed when sharp fluctuations in the average value stop when the sample size changes. The results are shown in Table 1.

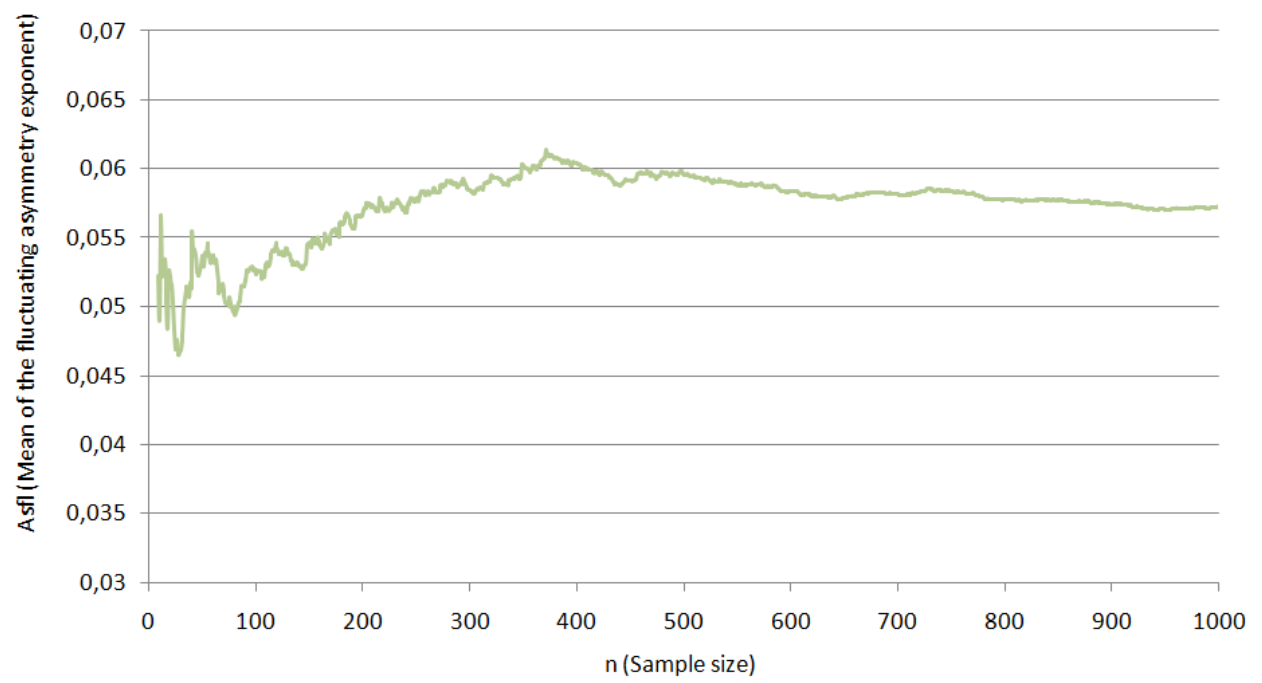

Fig. 2. Dependence of the fluctuating asymmetry of Betula pendula Roth on the sample size. Point 1 Waste recycling plant $(59.802549,30.134374)$.

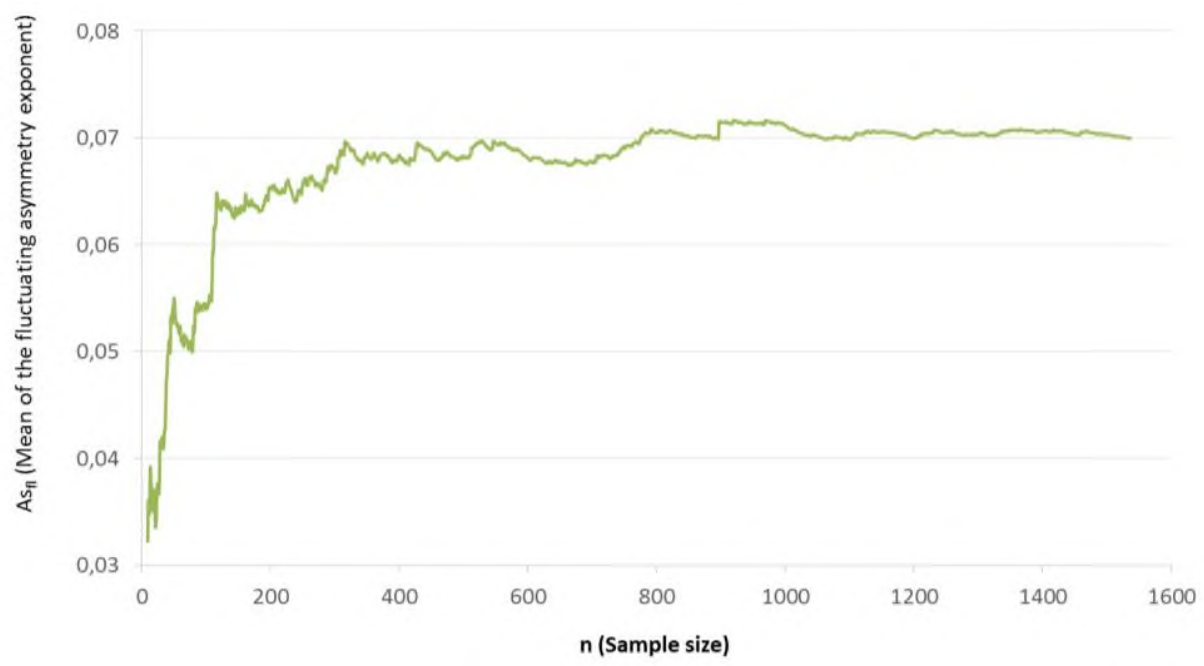

Fig. 3. Dependence of the fluctuating asymmetry of Betula pendula Roth on the sample size. Point 2 next to the ring road $(59.801728,30.143279)$. 


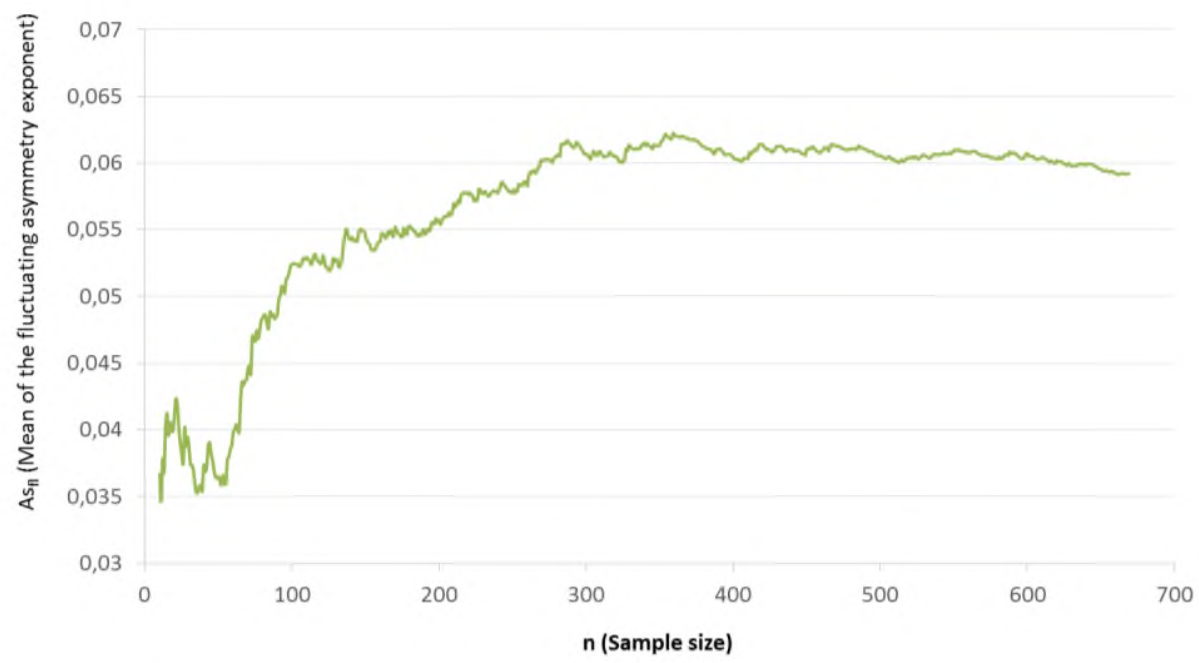

Fig. 4. Dependence of the fluctuating asymmetry of Betula pendula Roth on the sample size. Point 3 Alexandrino Park (59.828966, 30.234682).

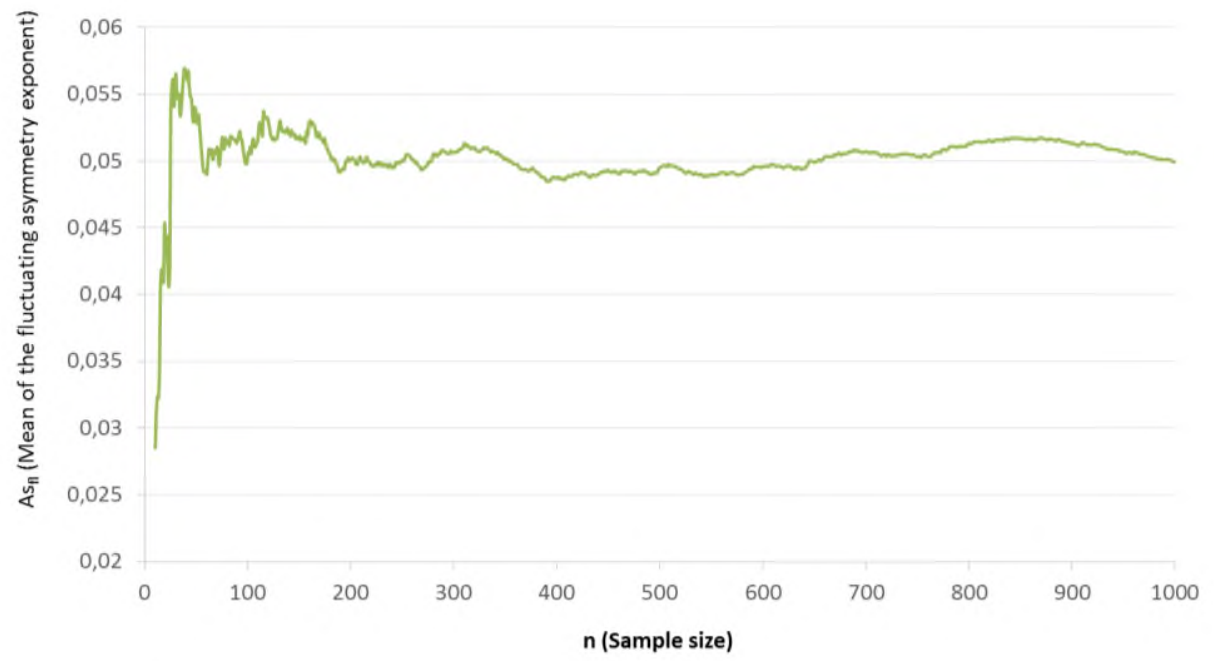

Fig. 5. Dependence of the fluctuating asymmetry of Betula pendula Roth on the sample size. Point 4 Novatorov Boulevard (59.845846, 30.268270).

The results show the dependence of the value of fluctuating asymmetry on the degree of ecological trouble. So, as expected, the maximum value of the fluctuating asymmetry coefficient is observed in the Gorelovo industrial zone near the ring road (point 2). The value of fluctuating asymmetry in the location of Aleksandrino Park (point 3), located next to the busy highway "Narodnogo Opolcheniya Avenue", railways and the ring road, was also expectedly high. The fluctuating asymmetry in the area of the waste recycling plant, a branch of the FSUE "Plant MPBO-2" Experimental plant for mechanized processing of municipal waste (point 1), turned out to be slightly less than the coefficient of fluctuating asymmetry of the silver birch growing in the Alexandrino Park. This circumstance is easily explained by the remoteness from the ring road, and most importantly, by the presence of a strip of green planting between the ring road and the herbarium collection point. Thus, the 
fluctuating asymmetry of silver birch in an industrial zone near a waste processing plant is less than in a park or forest belt located next to a busy highway. The smallest value of the coefficient of fluctuating asymmetry was found at the Novatorov Boulevard (point 4). This location is located in an area with heavy traffic, but at a considerable distance from the ring road. Thus, as expected, the most polluted locations in the South-West of St. Petersburg are located in the area of the ring road and the Western High-Speed Diameter.

Table 1. The coefficient of fluctuating asymmetry in industrial and recreational locations in the South-West of St. Petersburg.

\begin{tabular}{|c|c|c|c|c|c|}
\hline No. & $\begin{array}{c}\text { Herbarium sampling } \\
\text { point coordinates }\end{array}$ & $\mathrm{n}$ & $\min$ & $\max$ & Mean $\pm 1.96 * \mathrm{Sx} / \mathrm{V}_{\mathrm{n}}$ \\
\hline 1 & $59.802549,30.134374$ & 1001 & 0 & 0.413 & $(57 \pm 2)^{*} 10^{-3}$ \\
\hline 2 & $59.801728,30.143279$ & 1536 & 0 & 1.531 & $(69 \pm 4)^{*} 10^{-3}$ \\
\hline 3 & $59.828966,30.234682$ & 669 & 0 & 0.323 & $(59 \pm 4)^{*} 10^{-3}$ \\
\hline 4 & $59.845846,30.268270$ & 1000 & 0 & 0.333 & $(50 \pm 2)^{*} 10^{-3}$ \\
\hline
\end{tabular}

The use of bioindication to substantiate the priority of a sample for the isolation of destructors has limitations associated with the fact that the fluctuating asymmetry index depends on many factors and its use is rational only for ranking the samples taken compactly.

\section{Conclusions}

1. The index of fluctuating asymmetry of silver birch in an industrial location (Experimental plant for mechanized processing of municipal waste) can be comparable to a recreational location located near a highway with heavy traffic.

2. Parks of the South-West of St. Petersburg, located near the ring road, are promising for sampling for the isolation of highly effective strains - destructors of organic pollutants.

3. When isolating new strains-destructors from natural sources, it is advisable, in parallel with sampling, to collect herbarium at the sampling point in order to rank their priority using bioindication, but only for compactly selected samples.

This work was supported by the state mission of the Ministry of Science and Higher Education of the Russian Federation (785.00.X6019).

\section{References}

1. G. Kozlov, M. Pushkarev, V. Mokhna, Phenatrenebiodestructors isolated from soils of large cities, E3S Web of Conferences 135, 01052 (2019)

2. G. Kozlov, M. Pushkarev, A. Kozlov, E. Perepelitsa, Bioindication for the search of microorganisms-destructors, Advances in Intelligent Systems and Computing 1259 AISC, 676-684 (to be published 2021)

3. V.P. Ivanov, Yu.V. Ivanov, S.I. Marchenko, V.V. Kuznetsov, Application of Fluctuating Asymmetry Indexes of Silver Birch Leaves, Russian Journal of Plant Physiology 62(3), 340-348 (2015) doi: 10.1134/s1021443715030085

4. E. Kashparova, S. Levchuk, V. Morozova, V. Kashparov, A dose rate causes no fluctuating asymmetry indexes changes in silver birch (Betulapendula (L.) Roth.) leaves andScots pine (Pinussylvestris L.) needles in the Chernobyl Exclusion Zone, Journal of Environmental Radioactivity 211, 105731 (2020) doi: 10.1016/j.jenvrad.2018.05.015 
5. G.V. Kozlov, A.V. Garabadzhiu, A.V. Ankudinova, O.V. Ishchenko, Variety of destructors of polycyclic aromatic hydrocarbons, Russian Journal of General Chemistry 55, 1, 108-119 (2011) 